\title{
Analysis on the Development of Value-added Services of Logistics Enterprises in Yunnan
}

\author{
Kesheng Tang* \\ Kunming Metallurgy College \\ Kunming, China
}

\author{
Min Qian \\ Kunming Metallurgy College \\ Kunming, China
}

\author{
Bin Wang \\ Kunming Metallurgy College \\ Kunming, China
}

\begin{abstract}
In order to achieve the healthy and sustainable development of modern logistics enterprises, it is necessary to improve efficiency, cut costs and actively develop value-added services. The development of value-added services has become the consensus of logistics companies. In this paper we introduce the rese arch status quo of logistics value-added services firstly, as well as the status quo of Yunnan's logistics industry, and then summarize the existing types of logistics value-added services, finally put forward specific measures for the types and ways of value-added services carried out by logistics enterprises in Yunnan Province, which has certain practical and reference significance for other provinces.
\end{abstract}

Keywords-logistics enterprises; value-added services; modern logistics; Yunnan

\section{INTRODUCTION}

We know the seven functions of logistics: transportation, warehousing, packaging, handling, distribution, circulation processing and logistics information technology. Domestic scholars generally refer to circulation processing and logistics information technology as value-added services, and believe that circulation processing and logistics information technology are serving the other five main functions.

Domestic scholars' research on logistics value-added services is continuing. Dan Song studied the development strategy of logistics value-added services in Heilongjiang Province. He established the basic model of logistics enterprise profit, analyzed its profit source, and used linear regression theory, scale economy theory and elastic analysis theory to expound the shortcomings of logistics enterprises in providing value-added services. He also put forward a competitive strategy analysis about value-added services in the future in Heilongjiang Province[1]. Jian Qin focused on the importance of logistics enterprises to carry out value-added services, and conducted in-depth investigation and analysis on the status quo and problems of value-added services[2]. Aimin Yang pointed out that we can use the theory of supply chain management and customer relationship management to innovate the current logistics service model and put forward suggestions for diversified logistics value-added services[3].Y Song analyzed the problems leaded by application of mobile Internet of
Things in third-party logistics business and gave some suggestions [4]. L Chen discussed the location of value-added logistics services and its impact on supply chain configurations and logistics costs[5].

The current literature is more focused on the logistics industry as whole or individual issues. Many scholars and industry experts pointed out that in order to develop rapidly and enhance their core competitiveness for China's logistics enterprises, value-added services must be carried out. However, the development strategies of value-added services for logistics enterprises are often proposed from the strategic level of the industry or enterprises. There is little research on the valueadded service models adopted by specific small and mediumsized logistics enterprises.

\section{Development Status Quo of Logistics ENTERPRISES IN YUNNAN}

After issued the outline of logistics development planning by the national and local governments, leveraging the Belt and Road Initiatives, the development of logistics enterprises in Yunnan Province has ushered in a very good opportunity. In general, the development of logistics industry in Yunnan is still relatively backward, and it is in the process of transforming from traditional logistics to modern logistics. Due to the full competition in the logistics industry, the number of logistics enterprises has increased dramatically and their profits have fallen.

At present, logistics enterprises in Yunnan are developing rapidly, with more than 14,000 logistics enterprises and nearly 370,000 employees, forming a three-legged situation of local state-owned logistics, local private logistics and external logistics enterprises[6]. The mainstream logistics market in Yunnan is dominated by the local state-owned logistics enterprises, such as Yunnan Airport Logistics, Yunnan Tianma Logistics, Yunnan Baoxiang Logistics Group, Yunnan Transportation Group, Kunming Ship Logistics and the tobacco logistics enterprises. The private logistics companies in various cities in Yunnan have become a major supplement, such as Yunnan Haohong Logistics Group, Yunnan Gallops Logistics and Yunnan Shengda Logistics. The rapid entry of logistics companies such as China Railway Modern Logistics 
Technology, China Railway Express, ZJS Express, SF Express and other external logistics companies has effectively promoted Yunnan's logistics industry. However, most logistics enterprises in Yunnan are transformed from traditional warehousing and transportation enterprises. They are still providing simple service, such as warehouse storage, cargo transportation, and so on.

According to statistics, due to the increase in the cost of manpower, land, fuel, etc., the profit of logistics enterprises is only about $10 \%$, and they must also bear the risks in the operation process. In addition, about $85 \%$ of logistics companies' revenue comes from basic services such as transportation and warehousing, while value-added services of logistics accounts for only $15 \%[6]$.

In other words, the logistics enterprises in Yunnan have not yet fully transformed into modern logistics enterprises. They have not paid enough attention to value-added services, and they cannot clearly know how to carry out value-added services.

\section{Types of VAlue-Added SerVICES}

Value-added service is a kind of deep-level logistics service. It is a special value-added service plan that can be proposed after deep understanding of customers' logistics needs. It is a special service plan that meets specific logistics needs. Relying on the IT foundation of the enterprise, Value-added service is a technology and knowledge-intensive service that can provide information utility and risk utility[7]. In general, there are several types of value-added services as follows [8].

1. Carrier-type value-added service. Express transportation companies and container transportation companies that carry cargo transportation are most suitable for such value-added services. It includes tracking services from receipt to delivery, providing fast and reliable service for time-sensitive products and providing reliable services for temperature-demanding products such as refrigeration and refrigerated transportation.

2. Warehouse-type value-added service. Warehousing companies with large storage facilities can consider the following value-added services, such as attaching price tags and barcodes for satisfying customers' sales needs, providing low-temperature refrigeration services for food and pharmaceutical customers, to maximize the convenience of the merchant.

3. Freight forwarding type value-added service. It includes booking, chartering, consignment, cargo handling, container assembly and unpacking, distribution, customs declaration, inspection, insurance, multimodal transport and consolidation[9].

4. Information-based value-added service. Logistics service providers with information technology advantages can integrate information technology into logistics operations, such as using online technology to provide online data query and help services to customers.

5. Fourth party logistics value-added services. These services include providing a comprehensive supply chain solution for customers, integrating and optimizing logistics resources such as logistics enterprise management and technology, reengineering logistics operations and even reorganizing their organizational structures[10].

In short, regardless of the type, we should know that the value-added services should meet the following characteristics : convenience, quick response, reducing costs and extending the services. That is, we must provide convenience to downstream customers and enhancing customer experience, provide quick response to minimize logistics, simplify logistics, and improve the rapid response performance of the logistics system, provide the value-added services to reduce logistics costs for upstream customers and improve logistics efficiency and efficiency, provide the value-added services to extend up to market research and forecasting and to extend down to payment recovery and settlement.

\section{COUNTERMEASURES FOR THE DEVELOPMENT OF Logistics VAlue-AdDED SERVICES IN YunNan}

Value-added services have become an important source of profits for logistics companies. The logistics industry belongs to the service industry. The core of value-added services is how to provide customers with personalized services and services that can solve customers' "pain points". Only in this way valueadded services can be truly value-added, and it is also a necessary part of logistics enterprises to enhance their core competitiveness. Logistics enterprises in Yunnan must develop and provide value-added services according to the actual situation in Yunnan, in order to obtain sufficient growth in the fierce competition, especially small and medium-sized logistics enterprises.

1. Transportation enterprises can provide extended valueadded services by building advanced logistics information technology. For example, third-party transportation companies such as Yunnan Grand Star Logistics can provide customers with high-quality value-added services through the construction of advanced logistics information technology, including transportation route planning, in-transit monitoring and scheduling. Secondly, as an engineering logistics company, it can also provide simple value-added services for circulation processing, such as providing simple component cutting and complete components supply. Third-party transportation companies, such as Deppon Logistics, can provide customers with some value-added services, including inspection, collection, signing of receipts, comprehensive information services, delivery services, pick-up and custodial services.

2. The ordinary warehousing and distribution enterprises can provide extended value-added services such as circulation processing, recycling logistics and after-sales service. For example, Yunnan Xinchu Logistics Co. Ltd. provides customers with circulation processing such as packaging and labeling, and it can provide recycling services (electrical appliances and mobile phones) for customers. It is also possible to set up a department to meet the after-sales service of customers. The warehousing enterprise not only provides customers with warehousing and distribution of spare parts, but also provides after-sales service and recycling logistics services.

3. Resource-based warehousing enterprises can actively expand financial pledge services through building advanced 
information technology. In China, the pledge supervision business mainly consisting of steel, wood pulp, cotton, petroleum, polyethylene, polypropylene, automobile, etc. has models of warehouse receipt pledge and movable property pledge total control. The total amount of dynamic pledge control is the most widely used in raw materials. Yunnan has abundant resources and is suitable for carrying out financial pledge business of mineral resources.

At the same time, we should encourage logistics enterprises in Yunnan to explore agricultural product pledge business and avoid corresponding risks. As a new type of financing, agricultural product pledge provides a new way to alleviate the "financing difficulties" of small and medium-sized enterprises in agricultural areas. However, due to the biological attributes of agricultural products and the influence of market and price factors, how to effectively control the credit risk existing in the process of agricultural products as pledges has become a topic that must be solved.

4. After being bigger and stronger, the agricultural product logistics can establish standards and processes, expand the scale, and provide extended value-added services. Jinyuan Flower Logistics aims at the flower industry in Yunnan, establishes its own research and planting base, promotes planting to flower farmers, establishes standards and processes for flower planting, and invests in the establishment of a flower auction. It provides a series of value-added services such as planting technical support, packaging and cold chain for flower farmers, customers, logistics companies, etc. and has obtained considerable profits.

5. Logistics enterprises with sufficient capital flow and advanced information technology can provide fourth-party logistics value-added services. For example, Tiandihui Supply Chain Management Group is a company specializing in the distribution and operation of logistics parks. The company has advanced information systems and information technology, and is vigorously developing the participation of external vehicles. It provides extended value-added services, such as auto parts, tires, fuel oil, ETC cards, trailer tractors, containers and ecommerce. Value-added services are expected to become the company's main profit direction in the future.

6. Small and medium-sized logistics companies aim at large customers and can tailor their value-added service types. For example, Kunming Cheery Family Logistics is tailor-made for Yunnan Baiyao Group, which specializes in setting up a department to provide warehousing, door-to-door transportation, distribution and recycling logistics. Kerry Logistics specializes in providing finished and spare parts storage and distribution services, after-sales service and reverse logistics services for DELL computers.

7. Based on the special geographical location of Yunnan, under the background of the Belt and Road Initiatives, the value-added services of cross-border e-commerce logistics enterprises should provide multi-channel personalized service to facilitate the sale of goods in other countries.

\section{CONCLUSION}

Value-added services have become an important source of profit for logistics companies, and have gradually attracted their attention. Among the many existing logistics enterprises in Yunnan, about $80 \%$ of the logistics enterprises only carry out basic warehousing, distribution and transportation services, and have not provided various personalized value-added services. The value-added services provided must be able to meet the customer's needs, solve the customer's current "pain points", and must be personalized, tailor-made, and help customers enhance their core competitiveness. Of course, the types and projects of value-added services are not limited to the ones mentioned above; we need to continue to find out new value-added services, such as unified management and leasing of pallets. We can only find out more value-added service projects based on the current situation of the market and specific problems, so that modern logistics can achieve more profits and achieve better development.

\section{ACKNOWLEDGMENT}

Thanks the partners of the project team (Research Fund of Kunming Metallurgy College, No: 2016xjsk06) for their hard work in organizing the data. Thanks to the help of the collegeenterprise cooperation companies we visited.

\section{REFERENCES}

[1] Dan Song. "Research on the strategy of logistics value-added service development in Heilongjiang province”. Journal of Northeast Forestry University, Vol. 04, pp. 36-39, 2010(In Chinese)

[2] Jian Qin. "Discussion on the value-added service mode of logistics enterprises”. Logistics Engineering and Management, Vol.01, pp.37-38, 2015(In Chinese)

[3] Aimin Yang. "Diversified value-added logistics services model-logistics services innovation based on supply chain management and customer relation management theory". Journal of Wuhan University of Technology (Social Science Edition), Vol. 5, pp.470-473, 2002(In Chinese)

[4] Y Song. "Research on value-added services of third-party logistics based on mobile Internet of Things”. Shanghai, China, ICEE2012, pp.958961, May, 2012

[5] L Chen. "A cost perspective on the location of value-added logistics services in supply chains”. International Journal of Logistics Systems \& Management, Vol.18, pp.24-48, 2014

[6] Kesheng Tang. “Analysis on Logistics Dual-qualified Teachers' Construction of Higher Vocational Education under the Belt and Road Initiatives in Yunnan”, Qingdao, China, ICMED2017, pp.185-188, December 2017

[7] Lijun Yang. "Research on logistics value-added services based on supply chain collaboration”. Modern Logistics, Vol. 10, pp.74-76, 2016(In Chinese)

[8] Yongming Zhou. "Research on the meaning and implementation ways of logistics value-added services”. Reformation \& Strategy, Vol.11, pp.106-108, 2007(In Chinese)

[9] Zhiyong Fang. "Analysis of VA services of Chinese logistics enterprises existing problems and countermeasures thereof”. Logistics Technology, Vol. 5, pp.53-54, 2015(In Chinese)

[10] Kaifu Yuan. "Analysis on the development model of value-added services in logistics enterprises”. Foreign Trade Practice, Vol.12, pp.90-92, 2014(In Chinese) 